\title{
Stall Flutter Suppression for Absolutely Divergent Motions of Wind Turbine Blade Base on H-Infinity Mixed-Sensitivity Synthesis Method
}

\author{
Tingrui Liu*
}

\author{
College of Mechanical \& Electronic Engineering, Shandong University of Science \& Technology, Qingdao, China
}

\begin{abstract}
This paper is devoted to solve the problem of stall flutter suppression for an absolutely divergent blade of small scale wind turbine. The blade is specially designed with absolutely divergent motions for the purpose of determining the most effective methods of active control for stall flutter suppression. A 2-DOF blade section is considered, with a simplified stall nonlinear aerodynamic model being applied. H-infinity mixed-sensitivity synthesis method with a new three-weight regulation is designed to control the time-domain instability of aeroelastic equations, with a third weight being chosen to weight complementary sensitivity for tracking problems and noise attenuation to robust stabilization in $\mathrm{H}$ infinity control. Effects on flutter suppression are investigated based on different structural and external parameters. Apparent effects of H-infinity mixed-sensitivity method are displayed in the paper, when the other common intelligent control methods fail. The research provides a control way for absolutely divergent turbine blade motions.
\end{abstract}

Keywords: Flutter suppression, H-infinity mixed-sensitivity synthesis method, stall flutter, three-weight regulation.

\section{INTRODUCTION}

As typical nonlinear aeroelastic instable vibration, stall flutter is an important reason of fatigue damage for wind turbine. How to effectively avoid flutter instability has become an important subject needed to be investigated. Meanwhile in this area, the investigation of typical blade section based on the simplified stall flutter of 2-DOF flap/lag motions plays an important role due to its simplicity and high efficiency [1]. Hence in this study, stall flutter suppression will be depicted based on 2-DOF blade section.

In recent years, a number of issues related to the modeling, vibration analysis, and control methods for stall flutter are investigated. Shantanu experimentally studies and demarcates the stall flutter boundaries of an airfoil by measuring the forces and flow fields around the airfoil when it is forced to oscillate [2]. S. Sarkar investigates the effect of system parametric uncertainty on the stall flutter bifurcation behavior of a pitching airfoil, with the aerodynamic moment on the two-dimensional rigid airfoil being computed using the ONERA dynamic stall model [3]. J. Peiró investigates the dynamics of a typical airfoil section and demonstrates the importance of the added mass terms, with structural behavior being modeled by linear springs and the aerodynamic loading being exerted by Beddoes-Leishman (B-L) model [4]. Zhiwei adopts a nonlinear time-domain aeroservoelastic model and designs flutter suppression control systems, with a novel state-space model being descripted for control design [5]. Ananth presents a method to predict cascade flutter under subsonic stalled flow condition in a quasi-steady

*Address correspondence to this author at the College of Mechanical \& Electronic Engineering, Shandong University of Science \& Technology, No. 579, Qianwangang Road, Qingdao, Postcard: 266590, China;

Tel: +8615689977136; E-mail: liutingrui9999@163.com manner [6]. Jeroen analyzes a nonlinear dynamic problem of stall induced flutter oscillation subject to physical uncertainties using arbitrary polynomial chaos [7].

However all these issues related to stall flutter and control are focused on aircraft wing or rotorcraft blade rather than on wind turbine blade. Meanwhile the structural models are based either on coupling motions or on single-degree-offreedom motion. The aerodynamic models used are ONERA models or B-L models suitable for aircraft wing or rotorcraft blade.

The previous work of the author presents stall flutter research with suitable aerodynamic model for wind turbine in reference $[1,8]$. However the process and control are too complicated with coupling motions or pitch motion needs to be controlled, which is not suitable for research on specially designed blade of small scale wind turbine with absolutely divergent motions, for the purpose of determining the most effective methods of active control in a wide range. Although the methods of stall flutter suppression based on intelligent pitch control show great advantages [1,9], it is an expensive choice for small scale experimental blade, and of no practical use whatever.

In this paper, for the purpose of determining the most effective methods (with relatively simple and practical process) of active control for stall flutter suppression, the blade is specially designed with absolutely divergent motions, i.e. even if the wind speed $U$ is small $(U \geq 5 \mathrm{~m} / \mathrm{s})$, the system movement is still divergent. During the numerical simulation of solving problems of the absolutely divergent motions, much singularity will take place, which can lead to a broken-down control system in practice. 


\section{EQUATIONS OF MOTION}

The stall flutter investigation is simplified and based on the instability cases of a specially designed 2-DOF blade section located at a distance $r$ from the hub in Fig. (1). The structure is hinged in such a way that its motions have two independent translational degrees of freedom: a flapwise direction (Flap), denoted $z$; an edgewise direction perpendicular to that $(\mathrm{Lag})$, denoted $y$. The length of the blade $L=3 \mathrm{~m}$, the chord length $c=0.3 \mathrm{~m}$, the constant pitch angle is $\varphi$, the rotating speed is $\Omega$, and the tip speed ratio of wind turbine $\lambda=1.2$. For the specific designed section, it is assumed that the distance between the centre of gravity and the elastic axis is negligible; the distance between the aerodynamic centre and the elastic axis is negligible; so the elastic twist of the section might be negligible [1].

Using Lagrange's equations, the simplified linear structural model and equations of motion are derived from reference $[1,10]$, when rotating angular frequency is considered to be constant value. The equations of motion are as follows:

$\ddot{z}+2 \xi_{z} \omega_{z} \dot{z}+\omega_{z}^{2} z=\rho_{b}^{-1}\left(L_{C} \cos \psi+D \sin \psi\right)$

$\ddot{y}+2 \xi_{y} \omega_{y} \dot{y}+\omega_{y}^{2} y=\rho_{b}^{-1}\left(D \cos \psi-L_{C} \sin \psi\right)$

where $\omega_{\mathrm{y}}=7 \mathrm{rad} \mathrm{s}^{-1}$ and $\omega_{\mathrm{z}}=4 \mathrm{rad} \mathrm{s}^{-1}$ are natural angular frequencies, $\xi_{\mathrm{y}}=0.1$ and $\xi_{\mathrm{z}}=0.08$ are the damping ratios in $y$ and $z$ directions respectively. $\rho_{b}$ is the spanwise distribution of the density of the three-bladed stall-regulated rotor, which can be fitted as:

$$
\rho_{b}=\frac{\rho_{a} c^{2}}{10\left(p_{1} x^{5}+p_{2} x^{4}+p_{3} x^{3}+p_{4} x^{2}+p_{5} x+p_{6}\right)}
$$

where $\rho_{a}$ is the air density, and other constant parameters are

$p_{1}=44.94, p_{2}=-144.4, \quad p_{3}=180.3, p_{4}=-109.7$, $p_{5}=32.44, p_{6}=-3.412$

and $x=r / L, 0.3 \leq x \leq 1$.

The right-hand-side terms in Eq. (1) are aerodynamic expressions. A set of simplified ONERA aerodynamic model equations is extracted from references $[8,11]$, which is suitable for pure pitching motion [1]. The expressions for lift and drag aerodynamics used here are:

$$
\begin{aligned}
& L_{C}=\frac{1}{2} \rho S_{L}\left(V_{0}^{2} C_{1 L}+V_{0}^{2} C_{2 L}\right) \\
& D=\frac{1}{2} \rho c\left(0.014 V_{0}^{2}+V_{0}^{2} C_{D 2}\right)
\end{aligned}
$$

where the stall-induced items are:

$$
\begin{aligned}
& \dot{C}_{1 L}+\lambda_{L} \frac{V_{0}}{b} C_{1 L}=\lambda_{L} a_{0 L} \frac{V_{0}}{b} \phi \\
& \ddot{C}_{2 L}+a_{L} \frac{V_{0}}{b} \dot{C}_{2 L}+r_{L} \frac{V_{0}^{2}}{b^{2}} C_{2 L}=-r_{L} \frac{V_{0}^{2}}{b^{2}} \Delta C_{L} \\
& \ddot{C}_{D 2}+a_{D} \frac{V_{0}}{b} \dot{C}_{D 2}+r_{D} \frac{V_{0}^{2}}{b^{2}} C_{D 2}=-r_{D} \frac{V_{0}^{2}}{b^{2}} \Delta C_{D}
\end{aligned}
$$

where the constant aerodynamic parameters are expressed as:
$\Delta C_{L}=a_{x l} \alpha-0.1396 a_{L 1}-0.3142 a_{L 2}$,

$$
\begin{aligned}
& \left\{\begin{array}{cc}
a_{L 1}=0, a_{L 2}=0, & \alpha \leq 0.1396 \\
a_{L 1}=6.32284, a_{L 2}=0, & 0.1396<\alpha \leq 0.3142 \\
a_{L 1}=6.32284, a_{L 2}=-0.42284, & \alpha>0.3142
\end{array}\right. \\
& a_{x l}=a_{L 1}+a_{L 2} S_{L}=c, a_{0 L}=5.9, \lambda_{L}=0.15, \\
& V_{0}=\sqrt{U^{2}+r \Omega^{2}}, a_{L}=0.25+0.4\left(\Delta C_{L}\right)^{2}, \\
& r_{L}=\left[0.2+0.23\left(\Delta C_{L}\right)^{2}\right]^{2}, a_{D 1}=0.42, \\
& \Delta C_{D}=-a_{D 1} \alpha-a_{D 2} \alpha^{2}-a_{D 3} \alpha^{3}, r_{D}=\left[0.2+0.1\left(\Delta C_{L}\right)^{2}\right]^{2}, \\
& a_{D}=0.32, a_{D 3}=4.923, a_{D 2}=0.1437, \Omega=\lambda U / L .
\end{aligned}
$$

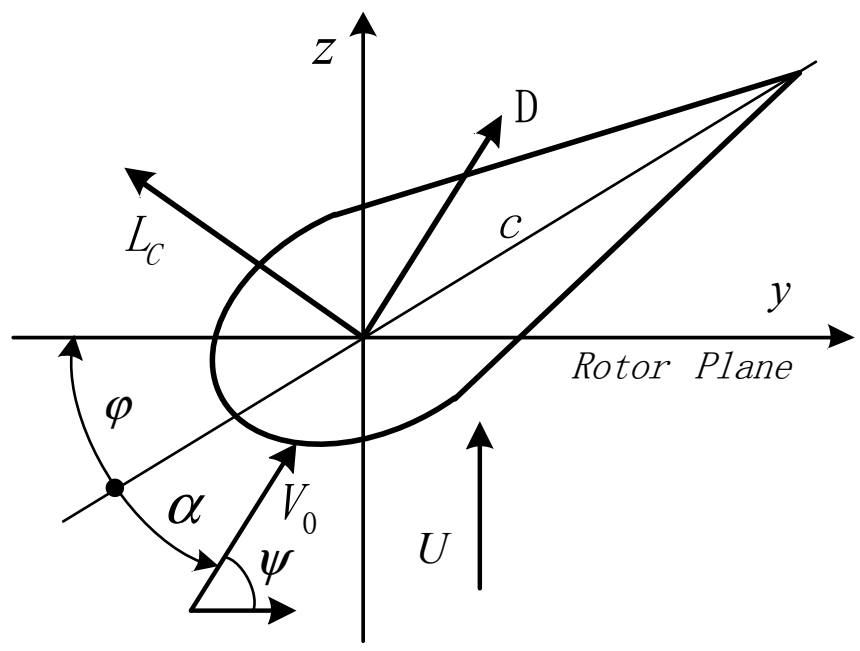

Fig. (1). Aerodynamic force and coordinate system.

\section{ANALYSIS OF ABSOLUTELY DIVERGENT MOTIONS}

To analyze the absolutely divergent motions, the following steps are implemented. Inserting Eqs. (2a)-(2b) into Eq. (1), and considering in conjunction with the stall-induced items of Eqs. (2c)-(2e), and assuming:

$X=\left[\begin{array}{lllll}z & y & C_{1 L} & C_{2 L} & C_{D 2}\end{array}\right]^{T}$

result in the governing stall aeroelastic system:

$M_{M} \ddot{X}+C_{M} \dot{X}+K_{M} X=Q_{M}$

To determine the time-domain response of the aeroelastic system of Eq. (3), Runge-Kutta approach is applied. Defining the state vector $Y=\left[X^{T}, \dot{X}^{T}\right]^{T}$, and adjoining the identity equation $\dot{X}=\dot{X}$, Eq. (3) will be expressed in statespace form:

$\left\{\begin{array}{c}\dot{Y}=A Y+B \\ Y_{O}=C Y+D\end{array}\right.$

where the $10 \times 10$ state matrix $A$ and $10 \times 1$ matrix $B$ are given by: 
$A=\left[\begin{array}{cc}z \operatorname{eros}(5) & I_{E} \\ -M_{M}^{-1} K_{M} & -M_{M}^{-1} C_{M}\end{array}\right], B=\left[\begin{array}{c}z \operatorname{eros}(5,1) \\ M_{M}^{-1} Q_{M}\end{array}\right]$

herein, $I_{E}$ is the unitary matrix, $C$ is unitary matrix and $D$ is $10 \times 1$ zero matrix.

For the absolutely divergent motions mentioned above, time-domain responses of flap/lag motions are illustrated, with basic structure parameters being $\varphi=45^{\circ}$ and $r=0.8 \mathrm{~L}$.

Fig. (2a-d) show the displacements of flap/lag motions based on wind speed $U$ from $5 \mathrm{~m} \mathrm{~s}^{-1}$ to $95 \mathrm{~m} \mathrm{~s}^{-1}$ at intervals of $30 \mathrm{~m} \mathrm{~s}^{-1}$, respectively. It can be seen that even if the wind speed is small, the flap/lag motions are still divergent. Furthermore the flutter amplitude increases rapidly, with the increase of wind speed.

\section{ACTIVE CONTROL STRATEGY}

Reference [1] investigates aeroservelastic pitch control based on intelligent control, such as optimal control, fuzzy control and neural network control, to realize stall flutter suppression. However, all these control strategies are based on complicated PID processes. It's not a kind of low cost strategy and of no practical use whatever for this specially designed small scale experimental blade. Simultaneously the independent intelligent control methods above are not adjustable and available in the present solution.

Further the linear quadratic gaussian (LQG) controller is often used to realize active flutter suppression for a multipleactuated-wing [12]. However in present study, the linear quadratic regulator failed to stabilize the plant or find an optimal feedback gain, it might be caused by the reason that not all unstable poles of matrix $A$ are controllable through $B$, or it is difficult to modify the weights in LQG controller to make related process positive definite [13].

In addition, a induced shear based mechanism is adopted for attaining active twist in a soft-inplane hingeless rotor to control vibration [14]. The single crystal macro fiber composite actuators and the aeroelastic analysis are designed and performed to control vibration for an active twist rotor blade [15]. Nonlinear limit cycle oscillations of an aeroelastic energy harvester are exploited for enhanced piezoelectric power generation from aerodynamic flows to control vibration [16]. Although in these works, the control properties indeed represent active control, the analytical objects are the torsional behavior of helicopter blades or the vibration behavior of airfoil in which stall flutter from stall aerodynamic action not mentioned, and what's more, to embed the third materials into small scale blade and analyze the flutter suppression behavior is a complex and difficult task.

\subsection{H-Infinity Mixed-Sensitivity Synthesis Method}

Motivated by the shortcomings of LQG control there was a significant shift towards $\mathrm{H}$-infinity optimization for robust control. There are many ways in which feedback design problems can be cast as H-infinity optimization problems [12]. The program listed in reference [13], can be used to (a) $U=5 \mathrm{~m} \mathrm{~s}^{-1}$

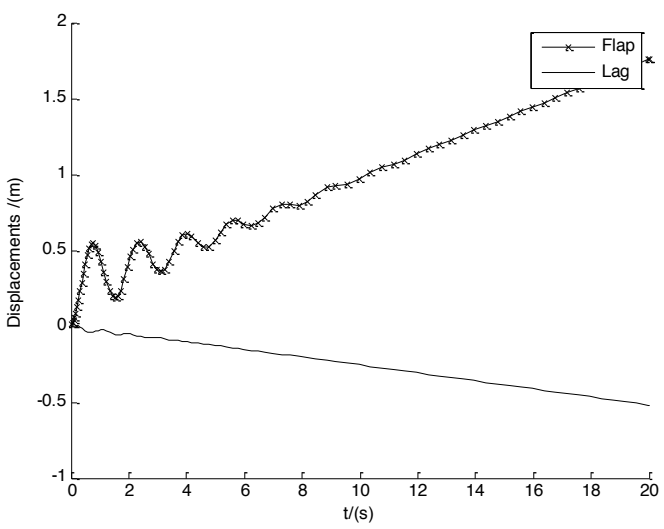

(b) $U=35 \mathrm{~m} \mathrm{~s}^{-1}$

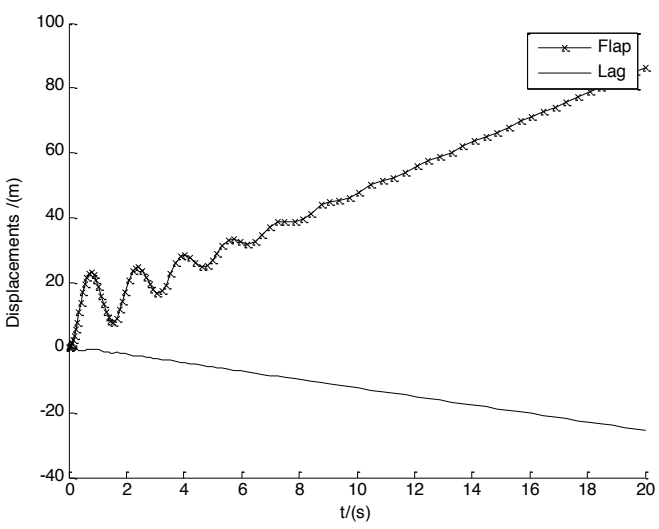

(c) $U=65 \mathrm{~m} \mathrm{~s}^{-1}$

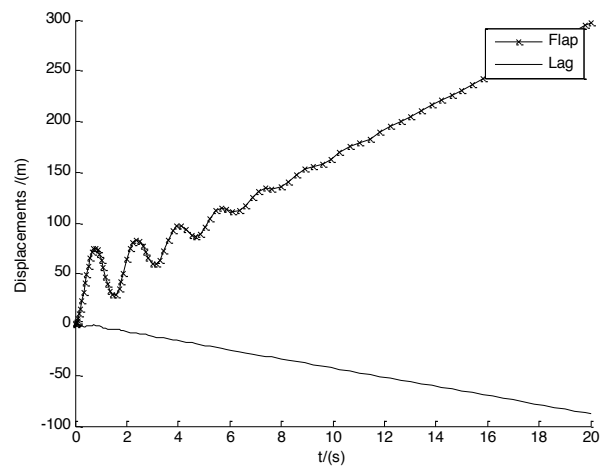

(d) $U=95 \mathrm{~m} \mathrm{~s}^{-1}$

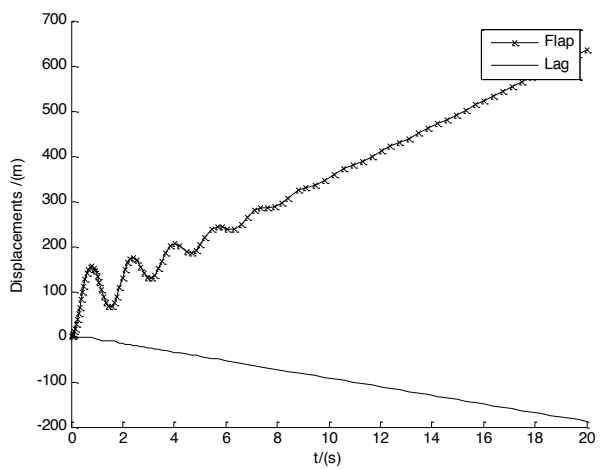

Fig. (2). Displacements of flap/lag motions based on wind speed $U$ from $5 \mathrm{~m} \mathrm{~s}^{-1}$ to $95 \mathrm{~m} \mathrm{~s}^{-1}$ at intervals of $30 \mathrm{~m} \mathrm{~s}^{-1}$, respectively. 
generate the H-infinity controller. It can get an explicit solution by solving just two Riccati equations and avoid the $\gamma$-iteration needed to solve the general $\mathrm{H}$-infinity problem.

However due to the absolutely divergent system here or because the designer is not able to specify any performance requirements in H-infinity optimization, the program in reference [13] fails. In order to evaluate and control such absolutely divergent system, H-infinity mixed-sensitivity (HMS) synthesis method is considered [16].

Mixed-sensitivity (MS) is the name given to transfer function shaping problems in which the sensitivity function $S$ is shaped along with one or more other closed-loop transfer functions. It is depicted as:

$S=(1+G K)^{-1}$

where $G$ is the plant from state-space form in Eq. (4), $K$ is the stabilizing controller. Most of MS problem is summarized as the two weights regulation method in practice to minimize:

$\left\|\left[\begin{array}{c}W_{1} S \\ W_{2} K S\end{array}\right]\right\|_{\infty}$

where $W_{\mathrm{i}}$ (typical $W_{\mathrm{i}}=1$ ) are the scalar weighting functions or matrices to shape $S$ and $K S$; herein, $W_{2}$ is a scalar high pass filter with a crossover frequency approximately equal to that of the desired closed-loop bandwidth.

In present study, in order to avoid failure of singularity in the solution, a method of three weights regulation is proposed in HMS synthesis method for robust control design. Controller $K$ stabilizes plant $\mathrm{G}$ and minimizes the $\mathrm{H}$ infinity cost function [17]:

$$
\left\|\left[\begin{array}{c}
W_{1} S \\
W_{2} K S \\
W_{3} T
\end{array}\right]\right\|_{\infty}
$$

where $T$ is complementary sensitivity, depicted as $T=I-S=$ $G K /(I+G K) ; W_{3}$ is chosen to weight $T$ for tracking problems (due to stall existence) and noise attenuation. Measurement noise might be produced by unsteady aerodynamics and hidden in system Eq. (4). $W_{3}$ is expressed as:

$W_{3}=\frac{(1 / M) s+w_{0}}{s+w_{0} A_{0}}$

where the weight parameters here are $A_{0}=1 \mathrm{e}-4, M=1.5, w_{0}=3$.

It should be stated that the values of $M, w_{0}$ play a key background role in solution. The smaller the values of $M, w_{0}$ are, the higher the control precision is. But if the values are too small, it will make the system collapse. Of course, if the simulation speed needs to be taken into account, the preferred choice is $W_{3}=1$.

The HMS minimization problem can be put into configuration as shown in Fig. (3), where the exogenous input is a reference command $r$, and the error signals are denoted by $z_{\mathrm{i}}$.

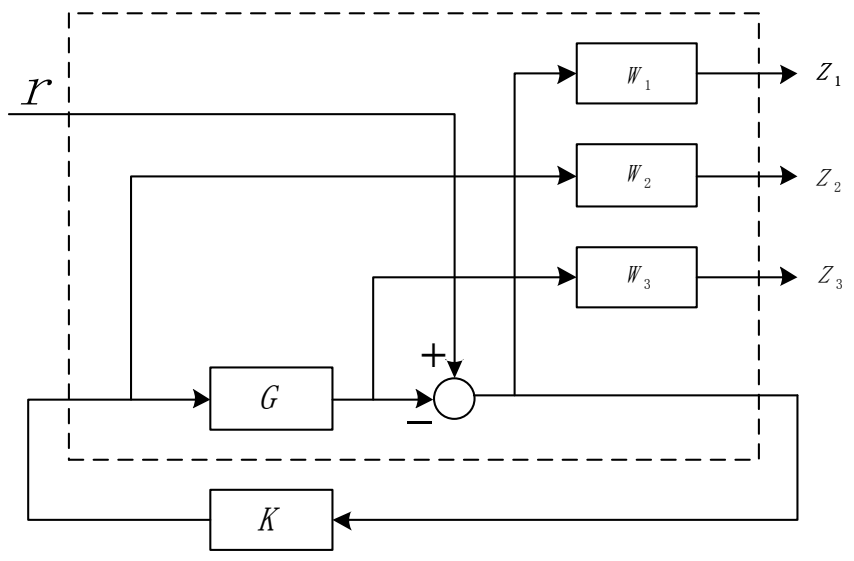

Fig. (3). HMS synthesis system with three weights regulation.

Fig. (4a-d) show displacements of flap/lag motions controlled by HMS synthesis method and corresponding amplitudes of controller $K$, based on cases and related parameters in Fig. (2). It can be seen that the HMS method is robust and the effects of flutter suppression are apparent, with all flag/lag responses being convergent. Even under the condition of high wind speed $U=95 \mathrm{~m} \mathrm{~s}^{-1}$ in Fig. (4d), HMS control can achieve good effects. However, under the condition of higher theoretical speed of $U \geq 65 \mathrm{~m} \mathrm{~s}^{-1}$ in Fig. $(\mathbf{4 c}, \mathbf{d})$, it is of little practical significance because the actual wind speeds in the land, are generally not more than $35 \mathrm{~m} \mathrm{~s}^{-1}$. In addition, as far as the amplitue of controller $K$ is concerned, it is perfectly acceptable with the maximum value within 0.025 .

\subsection{Discussions}

In order to testify the accuracy of HMS control, eigenvalues of both divergent examples (in Fig. 2) and HMS control examples (in Fig. 4) are considered based on the related parameters in Fig. (2). There are ten eigenvalues in every case of Fig. (2), with the two largest eigenvalues (real parts) always being zeros. However there are thirty-two eigenvalues in every case of Fig. (4), with all the real parts of eigenvalues being less than zeros. Taking the cases of $U=65$ $\mathrm{m} \mathrm{s}^{-1}$ in Fig. (2) and $U=65 \mathrm{~m} \mathrm{~s}$ in Fig. (4) for example, the ten eigenvalues of $U=65 \mathrm{~m} \mathrm{~s}^{-1}$ in Fig. (2) and the thirty-two eigenvalues of $U=65 \mathrm{~m} \mathrm{~s}^{-1}$ in Fig. (4) are listed in Table $\mathbf{1}$ in Appendix A.

According to Lyapunov's first indirect linearization method, the system stability is inconclusive for the left-hand plane (LHP, i.e. the poles of the system are located in the left-half plane) eigenvalues and one or more eigenvalues on the imaginary axis, as depicted in Table $\mathbf{1}$ for the case " $U=65$ $\mathrm{m} \mathrm{s}^{-1}$ in Fig. (2)". Hence the stability in Fig. (2) needs to be analyzed by time-domain response rather than eigenvalue analysis as mentioned above.

However for the cases in Fig. (4), all the real parts of eigenvalues in every case are less than zeros, as depicted in Table 1 for the case " $U=65 \mathrm{~m} \mathrm{~s}^{-1}$ in Fig. (4)", which indicates the absolute stability under control of HMS. The results of eigenvalue analysis are consistent with those of stability denoted by time-domain responses in Fig. (4). 
(a) $U=5 \mathrm{~m} \mathrm{~s}^{-1}$
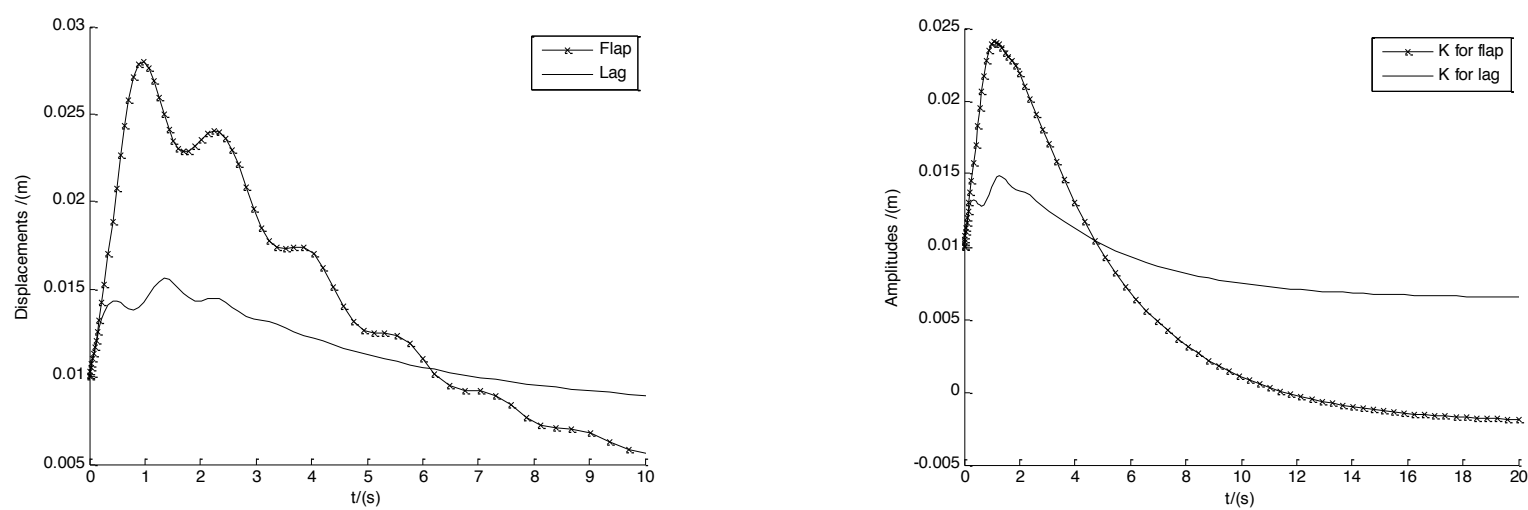

(b) $U=35 \mathrm{~m} \mathrm{~s}^{-1}$
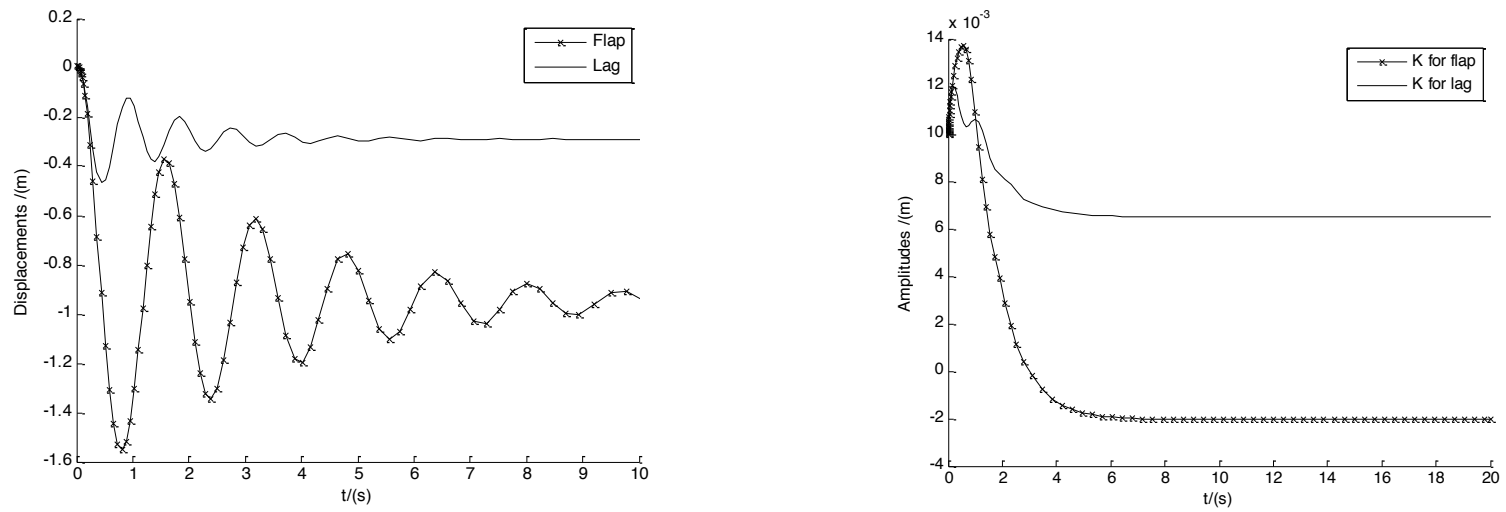

(c) $U=65 \mathrm{~m} \mathrm{~s}^{-1}$
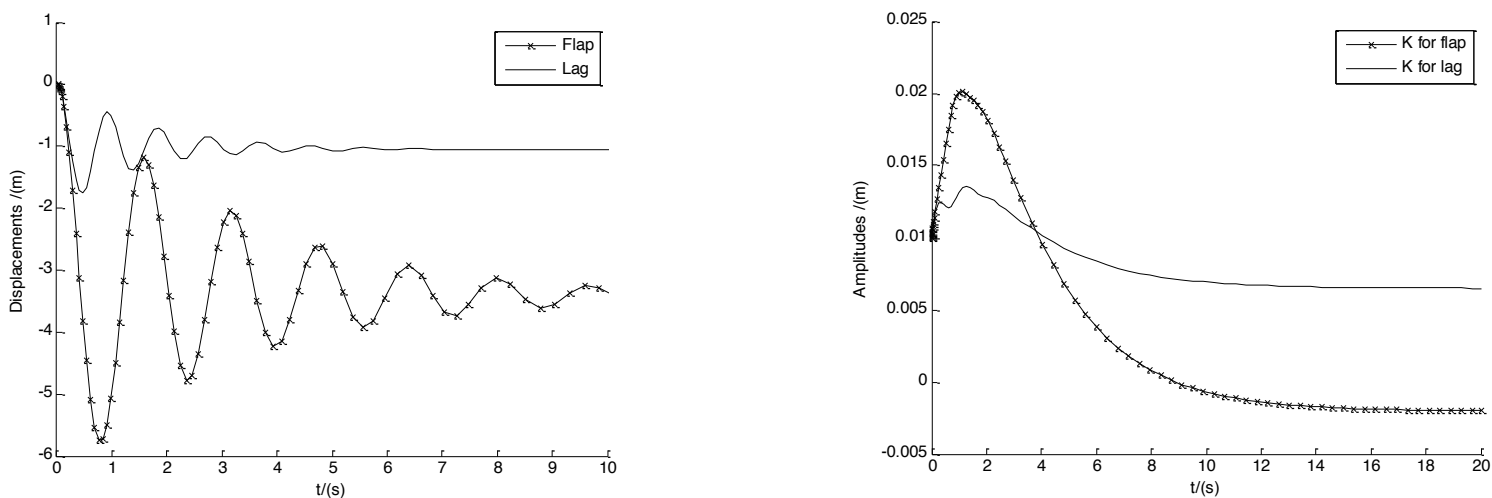

(d) $U=95 \mathrm{~m} \mathrm{~s}^{-1}$
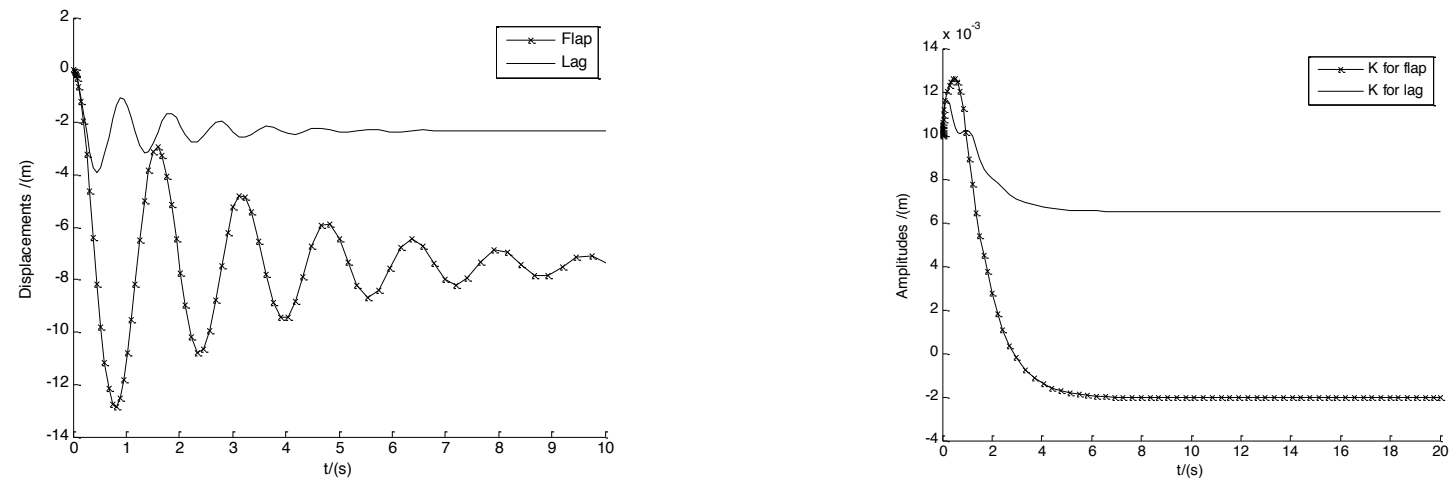

Fig. (4). Displacements of flap/lag motions controlled by HMS synthesis method and corresponding amplitudes of controller $K$ based on cases and related parameters in Fig. (2). 
In order to test such a HMS method can be commonly used at that given time and place, some cases of different positions $r$ (note that the minimum value of $r$ is $0.3 L$ ) and different pitch angles $\varphi$ are investigated, with wind speed being $U=15 \mathrm{~m} \mathrm{~s}^{-1}$ (the local maximum wind speed).

Fig. (5) shows time responses of flap and lag motions for distance $r$ from $0.3 L$ to $0.9 L$ at intervals of $0.2 L$, with pitch angle being $\varphi=\pi / 4$. It is demonstrated that the control effects in position $r=0.5 \mathrm{~L}$ (near the blade root) are the worst regardless of flap or lag, hence $r=0.5 \mathrm{~L}$ can be thought of as the dangerous cross section.

Fig. (6) shows time responses of flap and lag motions for pitch angle $\varphi$ from 0 to $\pi / 2$ at intervals of $\pi / 6$, in dangerous position of $r=0.5 \mathrm{~L}$. It can be seen that HMS control effects increase apparently with the increase of pitch angles, which agrees well with the results about influences of steady pitch angles in reference [1].

It should be noted that from the whole response trends in the cases of $r=0.5 \mathrm{~L}$ in Fig. (5) and $\varphi=0$ in Fig. (6), the flag/lag displacements both seem to be convergent. In fact the amplitudes of the flutter vibration quickly exceed the length of the blade $L$, so actually both of the displacements have been in the state of divergence.
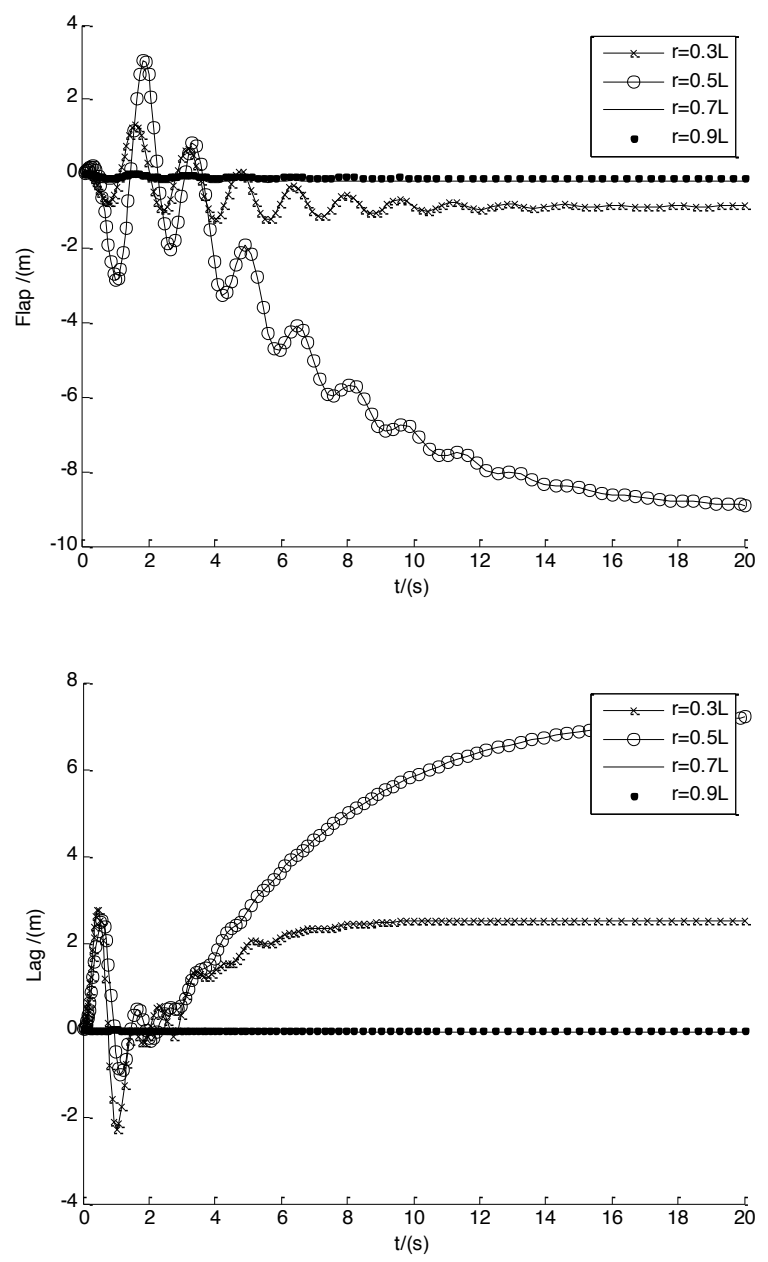

Fig. (5). Displacements of flap/lag motions for distance $r$ from $0.3 L$ to $0.9 \mathrm{~L}$ at intervals of $0.2 \mathrm{~L}$.
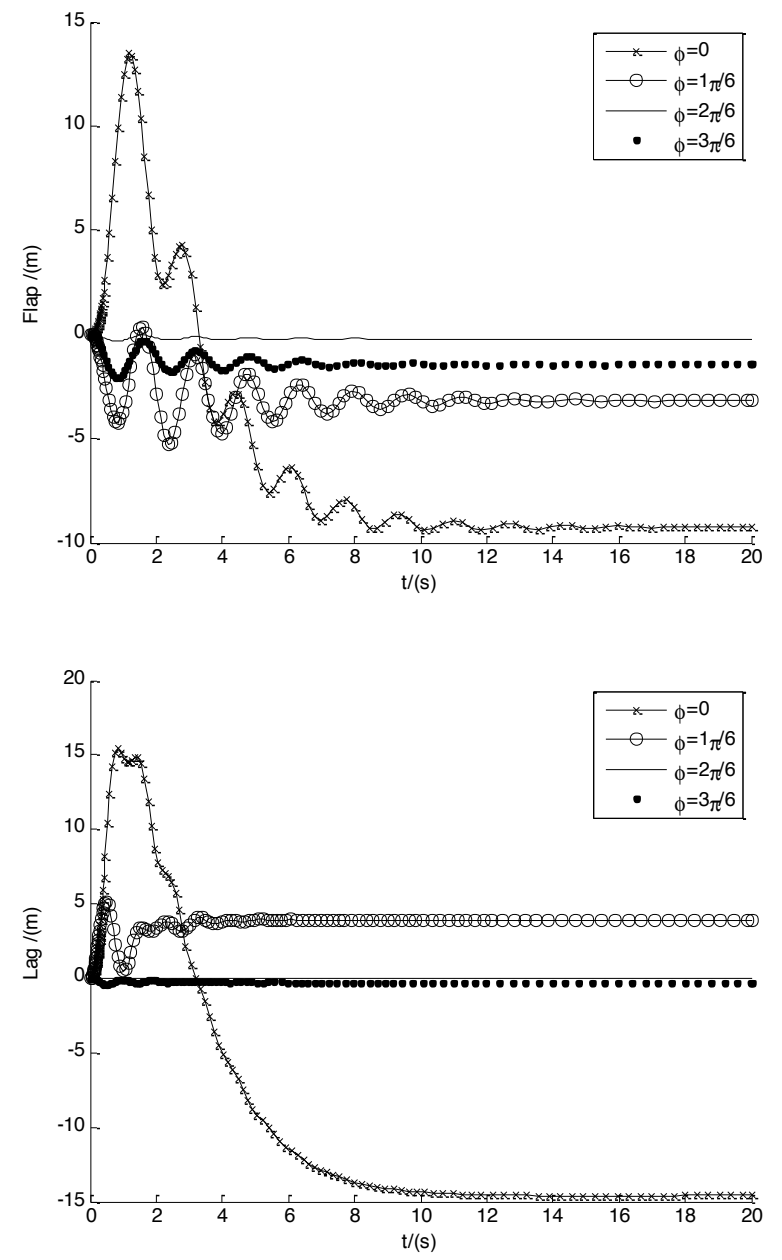

Fig. (6). Displacements of flap/lag motions for pitch angle $\varphi$ from 0 to $\pi / 2$ at intervals of $\pi / 6$.

\section{VALIDITY OF HMS CONTROL}

The effectiveness of HMS control can also be affirmed by some commercial software. The current trend in wind turbine design shows a significant progress in software development. Turbine blade manufacturers are aware of the fact that different design and conditions might introduce stall flutter and stability problems [18-21]. A software tool that simulates various control algorithms (including HMS control) and piezoelectric actuation performance was developed for this purpose. The software, named "Aeroelastic Control by Piezoelectric Actuation for Rotor Blade (ACPA) V1.1", was developed by Wind Energy Research Centre of SDUST in China [22]. The analysis programs are not only meant for evaluation of the aeroelastic stability but also to investigate flutter suppression with various control algorithms and piezoelectric actuation to enhance the aeroelastic instability characteristics. The software interface of ACPA is displayed in Appendix B.

The ACPA provides the user with control algorithms and piezoelectric actuation needed to test the controlled systems for flutter suppression within the MATLAB environment. The analysis is applied to a laminated host structure of the circumferentially asymmetric stiffness for a standard airfoil which produces flap bending-twist-transverse shear 
coupling. The spanwise distributed PZT-4 sensor-actuator pair is embedded into the orthotropic host. Specific program features include ACPA without feedback, ACPA with feedback for stall flutter, and ACPA with feedback for classical flutter (see Appendix B).

Taking the item of "ACPA with Feedback for Stall Flutter" for example, four controllers including optimal controller, linear quadratic regulation (LQR) controller, LQG controller and HMS controller are investigated. Under the default blade parameters of composite materials, piezoelectric materials and aerodynamic parameters in software, and with basic testing parameters of ply angle $\theta_{\mathrm{p}}$ $=30^{\circ}$, tip speed ratio of wind turbine $\lambda=3$, blade length $L=1.5$ $\mathrm{m}$, and the critical wind speed $U=34.69 \mathrm{~m} / \mathrm{s}$, the three displacements responses of vertical flap bending, twist, and transverse shear motions can be demonstrated, which are characterized by optimal controller, LQR controller, LQG controller and HMS controller.

Due to the limitation of paper length, only the displacements responses of flap bending $(v)$ are displayed here (see Fig. 7). As far as the trend of response is concerned, the three displacements of flap bending $v(L, t)$ based on LQR controller, LQG controller and HMS controller in Fig. 7 are rapidly convergent winthin $2 \sim 3$ s. Fig. (7c, d) also shows that the flutter amplitudes of flap displacements decrease rapidly with the change of time, and tend to be steady within $2 \mathrm{~s} \sim 3 \mathrm{~s}$. In particular, it shows obvious effect of HMS flutter suppression on aeroelastic instability.

\section{CONCLUSION}

In this study, stall flutter suppression of flag/lag motions of a specially designed blade section with absolutely divergent displacements are investigated based on simplified unsteady stall aerodynamic model. Moreover flutter suppression is implemented by $\mathrm{H}$-infinity mixed-sensitivity synthesis method. Some concluding remarks can be drawn from the results:

(1) The blade is specially designed for a small scale wind turbine, for the purpose of determining the most effective methods with relatively simple and practical process of active control for stall flutter suppression.

(2) H-infinity mixed-sensitivity synthesis method is implemented with a new three-weight regulation. The third weight is chosen for tracking problems and noise attenuation, in which the parameters are of the essence.

(3) It is obviously demonstrated that the method of HMS control is robust and the effects of flutter suppression are apparent. The conclusions in discussions are consistent with the related literature.

\section{CONFLICT OF INTEREST}

The author declares that there is no conflict of interest regarding the publication of this article. (a) Optimal controller

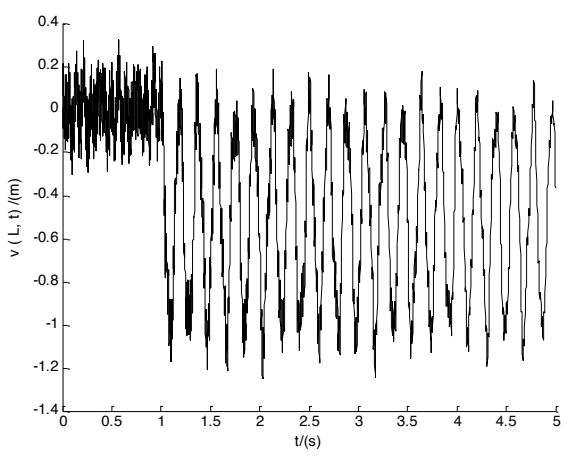

(b) LQR controller

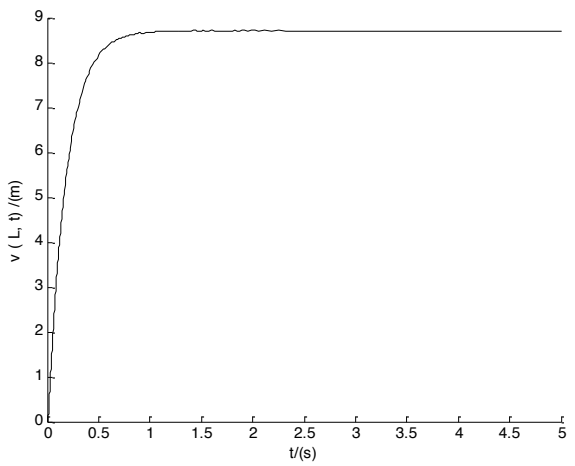

(c) LQG controller

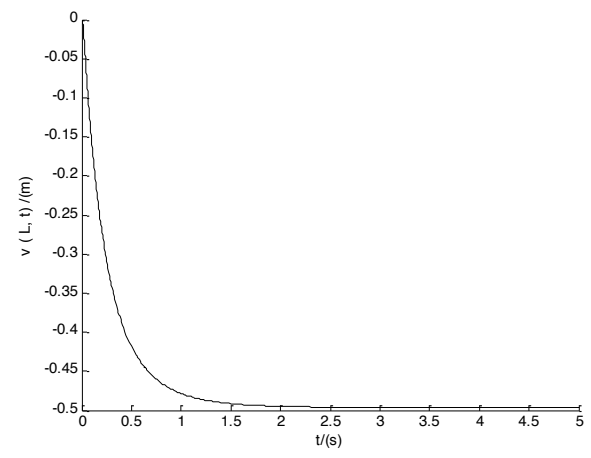

(d) HMS controller

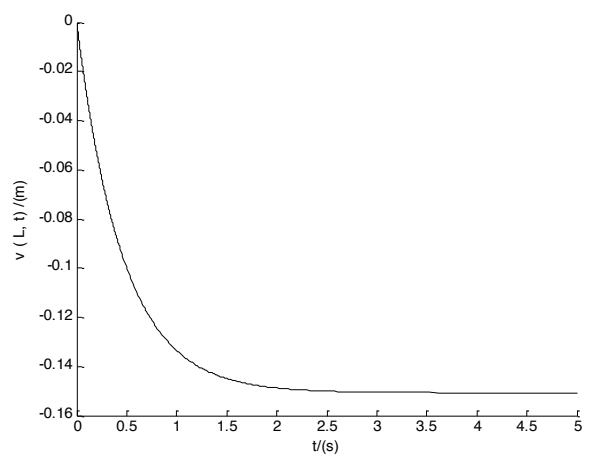

Fig. (7). Comparisions of the displacements responses of flap bending (v), which are characterized by optimal controller (a), LQR controller (b), LQG controller (c) and HMS controller (d).

\section{ACKNOWLEDGEMENTS}

This work is supported by the Natural Science Foundation of Shandong Province of China (ZR2013A M016). 


\section{APPENDIX A}

Table 1. The ten eigenvalues of the case " $U=65 \mathrm{~m} \mathrm{~s}^{-1}$ in Fig. (2)", and the thirty-two eigenvalues of "U=65 $\mathrm{m} \mathrm{s}^{-1}$ in Fig. (4)".

\begin{tabular}{|c|c|}
\hline Eigenvalues for $U=65 \mathrm{~m} \mathrm{~s}^{-1}$ in Fig. (2) & Eigenvalues for $U=65 \mathrm{~m} \mathrm{~s}^{-1}$ in Fig. (4) \\
\hline 0 & $-3.0000 \mathrm{e}-004$ \\
\hline 0 & $-3.0000 \mathrm{e}-004$ \\
\hline$-3.2000 \mathrm{e}-001-3.9872 \mathrm{e}+000 \mathrm{i}$ & $-3.0000 \mathrm{e}-004$ \\
\hline$-3.2000 \mathrm{e}-001+3.9872 \mathrm{e}+000 \mathrm{i}$ & $-3.0000 \mathrm{e}-004$ \\
\hline$-4.0772 \mathrm{e}+000$ & $-3.0000 \mathrm{e}-004$ \\
\hline$-7.0000 \mathrm{e}-001-6.9649 \mathrm{e}+000 \mathrm{i}$ & $-3.0000 \mathrm{e}-004$ \\
\hline$-7.0000 \mathrm{e}-001+6.9649 \mathrm{e}+000 \mathrm{i}$ & $-3.0000 \mathrm{e}-004$ \\
\hline$-9.6111 \mathrm{e}+001-7.2083 \mathrm{e}+001 \mathrm{i}$ & $-3.0000 \mathrm{e}-004$ \\
\hline$-9.6111 \mathrm{e}+001+7.2083 \mathrm{e}+001 \mathrm{i}$ & $-3.0000 \mathrm{e}-004$ \\
\hline \multirow[t]{23}{*}{$-3.5400 \mathrm{e}+003$} & $-3.0000 \mathrm{e}-004$ \\
\hline & $-3.0000 \mathrm{e}-004$ \\
\hline & $-3.0000 \mathrm{e}-004$ \\
\hline & $-3.0000 \mathrm{e}-004$ \\
\hline & $-3.0000 \mathrm{e}-004$ \\
\hline & $-3.0000 \mathrm{e}-004$ \\
\hline & $-3.0000 \mathrm{e}-004$ \\
\hline & $-3.0000 \mathrm{e}-004$ \\
\hline & $-3.0000 \mathrm{e}-004-1.0713 \mathrm{e}-014 \mathrm{i}$ \\
\hline & $-3.0000 \mathrm{e}-004+1.0713 \mathrm{e}-014 \mathrm{i}$ \\
\hline & $-3.7154 \mathrm{e}-001$ \\
\hline & $-1.0000 \mathrm{e}+000$ \\
\hline & $-3.2000 \mathrm{e}-001-3.9872 \mathrm{e}+000 \mathrm{i}$ \\
\hline & $-3.2000 \mathrm{e}-001+3.9872 \mathrm{e}+000 \mathrm{i}$ \\
\hline & $-1.4965 \mathrm{e}+000-5.8995 \mathrm{e}+000 \mathrm{i}$ \\
\hline & $-1.4965 \mathrm{e}+000+5.8995 \mathrm{e}+000 \mathrm{i}$ \\
\hline & $-7.0000 \mathrm{e}-001-6.9649 \mathrm{e}+000 \mathrm{i}$ \\
\hline & $-7.0000 \mathrm{e}-001+6.9649 \mathrm{e}+000 \mathrm{i}$ \\
\hline & $-9.6111 \mathrm{e}+001-7.2083 \mathrm{e}+001 \mathrm{i}$ \\
\hline & $-9.6111 \mathrm{e}+001+7.2083 \mathrm{e}+001 \mathrm{i}$ \\
\hline & $-9.6074 \mathrm{e}+001-7.8602 \mathrm{e}+001 \mathrm{i}$ \\
\hline & $-9.6074 \mathrm{e}+001+7.8602 \mathrm{e}+001 \mathrm{i}$ \\
\hline & $-3.4482 \mathrm{e}+003$ \\
\hline
\end{tabular}

\section{APPENDIX B}

\section{Software Interface of ACPA}

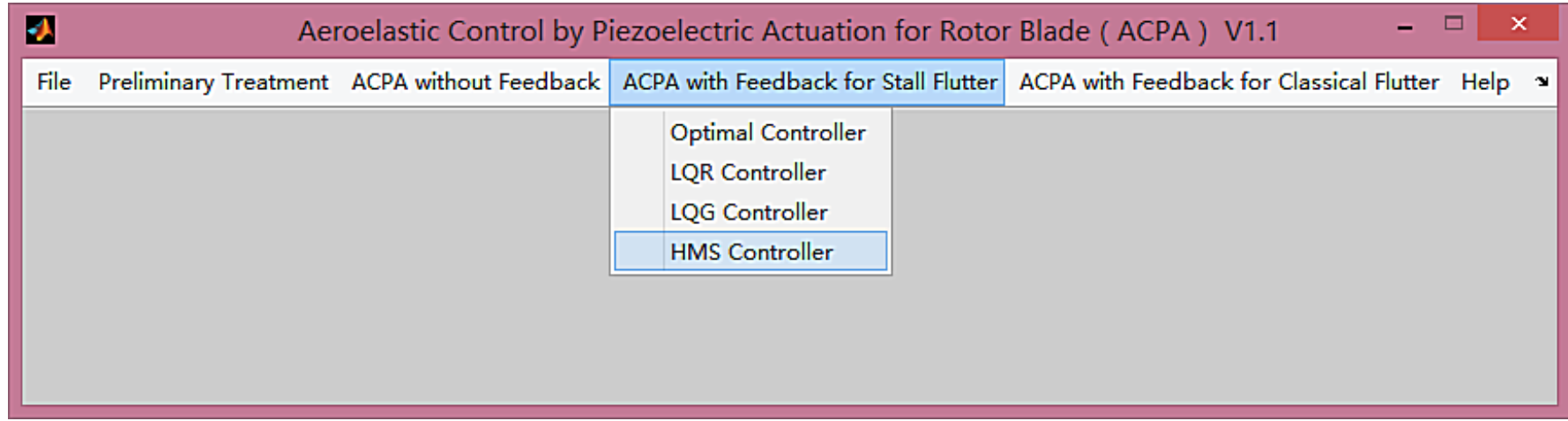




\section{REFERENCES}

[1] T. Liu, "Aeroservoelastic pitch control of stall-Induced Flap/Lag flutter of wind turbine blade section", Shock and Vibration, vol. 2015, pp. 1-20, 2015.

[2] S. B. Shantanu, and N. Raghuraman, "Stall flutter of NACA 0012 airfoil at low Reynolds numbers", Journal of Fluids and Structures, vol. 41, pp. 166-174, 2013.

[3] S. Sarkar, J. A. S. Witteveen, A. Loeven, and H. Bijl, "Effect of uncertainty on the bifurcation behavior of pitching airfoil stall flutter", Journal of Fluids and Structures, vol. 25, no. 2, pp. 304320, 2009.

[4] J. Peiró, U. Galvanetto, and C. Chantharasenawong, "Assessment of added mass effects on flutter boundaries using the LeishmanBeddoes dynamic stall model", Journal of Fluids and Structures, vol. 26 , no. 5, pp. 814-840, 2010

[5] Z. Sun, S. Haghighat, H.T. Liu, and J. Bai, "Time-domain modeling and control of a wing-section stall flutter", Journal of Sound and Vibration, vol. 340, no. 31, pp. 221-238, 2015.

[6] S. M. Ananth, A. Kushari, and C. Venkatesan,"Quasi-steady prediction of coupled bending-torsion flutter under rotating stall", Journal of Fluids and Structures, vol. 43, pp. 402-427, 2013.

[7] J. A. S. Witteveen, S. Sarkar, and H. Bijl, "Modeling physical uncertainties in dynamic stall induced fluid-structure interaction of turbine blades using arbitrary polynomial chaos", Computers \& Structures, vol. 85, no. 11-14, pp. 866-878, 2007.

[8] T. Liu, Y. Ren, and X. Yang, "Nonlinear aeroelastic stability analysis of wind turbine blade with bending-bending-twist coupling", Journal of Fluids and Structures, vol. 42, pp. 488-502, 2013.

[9] A. S. Yilmaz, and Z. Özer, "Pitch angle control in wind turbines above the rated wind speed by multi-layer perceptron and radial basis function neural networks", Expert Systems with Applications, vol. 36, pp. 9767-9775, 2009.

[10] B. S. Kallesøe, "A low-order model for analyzing effects of blade fatigue load control", Wind Energy, pp. 421-436, 2006.
[11] T. Kim, and J. Dugundjit, "Nonlinear large amplitude aeroelastic behavior of composite rotor blades", AIAA Journal, vol. 31, no. 8, pp.1489-1497, 1993.

[12] W. Qian, R. Huang, and H. Hu, Y. Zhao, "Active flutter suppression of a multiple-actuated-wing wind tunnel model", Chinese Journal of Aeronautics, vol.2015, pp.1-15, 2015.

[13] S. Skogestad, and I. Postlethwaite, Multivariable Feedback Control: Analysis and Design, $2^{\text {nd }}$ ed., Chichester: Wiley, 2005

[14] T. Dipali, and G. Ranjan, "Induced shear actuation of helicopter rotor blade for active twist control", Thin Wall Struct, vol. 45, pp.111-121, 2007.

[15] J. S. Park, and J. H. Kim, "Design and aeroelastic analysis of active twist rotor blades incorporating single crystal macro fiber composite actuators", Composites Part B, vol.39, pp. 1011-1125, 2008.

[16] J. A. Dunnmon, S. C. Stanton, and B. P. Mann, E. H. Dowell, "Power extraction from aeroelastic limit cycle oscillations", Journal of Fluids and Structures, vol. 27 pp. 1182-1198, 2011.

[17] D. Xue, Computer Aided Control Systems Design Using MATLAB Language, $2^{\text {nd }}$ ed., Tsinghua University Publishing Company, Beijing, 2006.

[18] G. Mowry, R. Erickson, and J. Abraham, "Computational model of a novel, two-cup horizontal wind-turbine system", The Open Mechanical Engineering Journal, vol. 3 pp. 26-34, 2009.

[19] L. Zhao, M. Liu, "Aerodynamic characteristics of asymmetric airfoils blade small vertical axis wind turbines", The Open Mechanical Engineering Journal, vol. 8, pp. 750-753, 2014.

[20] L. Zhang, H. Liu, and M. Zhang, H. Yie, "Determination method of critical best tip speed ratio for the vertical axis wind turbine", The Open Mechanical Engineering Journal, vol. 9 pp. 320-323, 2015.

[21] Y. Zhang, F. Xiong, and S. Yang, "Numerical simulation for composite wing structure design optimization of a minitype unmanned aerial vehicle", The Open Mechanical Engineering Journal, vol. 5, pp. 11-18, 2011.

[22] T. Liu, Aeroelastic Control by Piezoelectric Actuation for Rotor Blade. CN2015R11L240052 (2015).

(C) Tingrui Liu; Licensee Bentham Open.

This is an open access article licensed under the terms of the (https://creativecommons.org/licenses/by/4.0/legalcode ), which permits unrestricted, non-commercial use, distribution and reproduction in any medium, provided the work is properly cited. 